\title{
Lifestyle And Effective Factors On It Among Patients With Transient Ischemic Attack
}

\author{
Tahere Sarboozi Hosein $^{1 *}$, Shahrzad Ghiyasvandian ${ }^{2}$, M asoome Zakeri M oghadam ${ }^{3}$, Anooshiravan Kazemnejad ${ }^{4}$ \\ ${ }^{1}$ M aster of Nursing, faculty of Torbat Heydariyeh University of Medical Sciences , Torbat Heydariyeh, Iran. \\ ${ }^{2}$ Nursing Ph.D, Associate Professor of Surgical Nursing Department in Nursing and Midwifery college, Tehran \\ University of Medical science, Tehran, Iran. \\ ${ }^{3}$ Nursing Education Ph.D, Associate Professor of Nursing and M idwifery college, Tehran University of M edical science, \\ Tehran, Iran. \\ ${ }^{4}$ Biostatistical Ph.D, professor and faculty member of Tarbiat Modares, Tehran, Iran. \\ *Corresponding Author: Email: Taheresarboozi@yahoo.com
}

\section{Background}

Choosing wrong type of lifestyle by a person can predispose him/her to cardiovascular disease such as strokes, which can be a serious hazard for his/her health. Transient ischemic attack is a transient attack of impaired brain function disorder that can predict further strokes. Therefore, this study has done by the purpose of defining lifestyle condition about the patients with transient ischemic attack.

\section{Material and methods}

This study is the analytic-descriptive type and has been conducted on 60 patients with transient ischemic attack that admitted to the chosen hospital of Tehran, by random sampling method in 1394 . The research tools were patient condition demographic questionnaire and health promotion lifestyle profile (HPLP II). The collected data were analyzed by the SPSS 16 software and statistical tests.

\section{Findings and results}

Lifestyle of $63.25 \%$ of patients estimated at medium level. Physical activity, stress management and health responsibility dimensions also had lower score in comparison with other dimensions. Interpersonal relationships dimension had the highest score. Statistically significant relation has seen among the lifestyle and education level and economic situation $(P<0.05)$

\section{Conclusion}

Improvement and promotion of patient's lifestyle, especially from the point of physical activity and stress management, requires more attention and by considering the fact that the main cause of stroke is related to person's lifestyle, the necessity of training programs implementation, in order to change or preserve these patients' lifestyle, is recommended.

Key words: Lifestyle, Stroke, Transient Ischemic Attack

DOI: 10.7575/aiac.abcmed.ca1.30

A I Published Date: February 2017

Peer-review is under responsibility of the 9th Iranian Stroke Congress.

Published by Australian International Academic Centre, Australia

This published work is open access under the CC BY license.

Available online at www.abcmed.aiac.org.au 